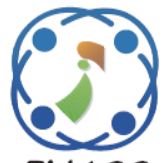

\title{
A Novel Neural Network SC_MRAS Based Observer for High-Performance SPIM Drives
}

\author{
Ngoc Thuy Pham ${ }^{1 *}$ \\ Diep Phu Nguyen ${ }^{1}$ \\ Khuong Huu Nguyen ${ }^{2}$ \\ Nho Van Nguyen ${ }^{3}$ \\ ${ }^{1}$ Dept. of Electrical Engineering Technology, Industrial University of Ho Chi Minh City, VietNam \\ ${ }^{2}$ Dept. of TE and Electrical Engineering, Ho Chi Minh City University of Transport, VietNam \\ ${ }^{3}$ Dept. of Electrical and Electronics Engineering, University of Technology Ho Chi Minh City, VietNam \\ * Corresponding author's Email: ngocpham1020@gmail.com
}

\begin{abstract}
In this paper, a novel Stator Current Model Reference Adaptive System (SC_MRAS) based scheme using Neural Network (NN) for sensorless controlled of Six Phase Induction Motor (SPIM) drive is presented. For this scheme, the measured stator current components are used as the reference model to avoid the pure integrator problems and reduce influence of motor parameter variation. The two layer linear NN stator current observer is used as an adaptive model, which has been trained online by means of a Back Propagation Network (BPN) algorithm, to estimate rotor speed and update stator resistance value. The Voltage Model (VM) based rotor flux identifier with value of stator resistance is updated online is used to provide the rotor flux for the adaptive model, this helps to overcome the instability problem in the regenerating mode of operation that occur when using current model for rotor flux identifier and enhance the low speed operation performance of the proposed scheme. Simulation results have demonstrated that the proposed MRAS observer is significantly improved especially at low and near zero speed range, Sensorless results also confirm the instability problem not exist in the regenerating mode in low speed region.
\end{abstract}

Keywords: MRAS observer, Neural network, Sensorless vector control, Six phase induction motor drive.

\section{Introduction}

In recent decades, the multiphase motors have been proposed by the authors [1]. The main advantages of multiphase motors are higher torque density, greater efficiency, reduced torque pulsations, fault tolerance, and reduction in the required rating per inverter leg [1]. Therefore, multiphase motors are often considered in some applications such as locomotive traction, electrical ship propulsion, in high power applications such as automotive, aerospace, military and nuclear [2]. With its reliable working characteristics and high failure tolerance nowadays, this motors are even considered in the small power applications requiring high reliability and fault tolerance, where are expected that the loss of one or more phases the machine still can provide a significant electromagnetic torque to continue operating the system. Among the many types of multiphase motors, SPIM is one of the most widely used multiphase motors.

The high performance SPIM drives require the rotor speed information. This can be obtained through a speed sensor or be estimated through the values of stator voltage and current. The use of speed sensor is associated with problems as reduction of reliability and mechanical robustness of the drives and cost increase, need of shaft extension and injects noise into the system. Moreover, in certain applications it is difficult to mount sensors. Therefore, different techniques for the speed sensorless control of induction motors have been proposed. They usually are divided into two categories, the fundamental model based observers and anisotropies model based observers. Modelbased estimation strategies include open-loop observers [3], sliding-mode observers [4], extended and unscented Kalman filters [5], Model Reference Adaptive Systems (MRAS) [6, 7] and Artificial 
Intelligence (AI) [8]. Recent research also used predictive current control for sensorless IM drives [9]. The main drawback of these model based observers are their insufficient performance at low speeds and machine parameter sensitivity. In order to overcome these problems a high frequency voltage or current carrier were injected, needed to excite the saliency itself [10]. A different approach lies in trying to track the rotor slotting effect directly, without any high frequency carrier excitation [11]. These methods work well at low and near zero speed region. However, their major disadvantages are computational complexity, the need of external hardware for signal injection and the adverse effect of injecting signal on the machine performance. Therefore, because of its simplicity and ease of implementation the model based methods and especially MRAS based methods are, until now, the most widely used.

There are the different MRAS techniques to estimating the rotor speed for the high performance IM drives have been proposed. The MRAS schemes have been proposed in the literature based on rotor flux proposed by Schauder Rotor-flux MRAS (RFMRAS) [12]. This scheme suffers from DC drift problems associated with pure integration and sensitivity to stator resistance variations, especially in the low speed regions. The back-EMF MRAS scheme was introduced to overcome the pure integration problem [13]. However, this scheme is difficult to design its adaptation gain constants and sensitive to stator resistance variations. The Reactive Power MRAS (RP-MRAS) scheme is immune to stator resistance variations but its disadvantage is instability in regenerating mode [14]. Another approach, the stator current MRAS scheme has been introduced by the authors for the speed identification of Induction Motor (IM) drives [15]. Simulink and experimental results have showed that the significantly improvement in low speed operation performance. However, this proposed strategy were also instability in the regenerating mode of operation. In order to overcome instability problem in $[15,16]$, a solution have been proposed in [17], a neural network is used to off-line rotor flux identifier instead of using Current Model (CM). However, since this scheme needs two individual $\mathrm{NN}$ to estimate the stator current and rotor flux, computational burden required by $\mathrm{NN}$ comparing to a simple mathematical equation of the CM or VM is a large drawback of the proposed strategy.

This paper proposes an improvement of the MRAS speed observer based stator current presented in [17]. In this paper, a new SC_MRAS using NN and VM (NNVM_SC_MRAS) scheme is proposed using the reference model comprises the measured stator current components to it free of pure integration problems and insensitive to motor parameter variations. A two layer linear NN stator current observer is used as an adaptive model where the rotor speed and stator resistor are two of the neural network weights. A backpropagation learning algorithm is used to train the $\mathrm{NN}$ online to update the value of stator resistor and estimate rotor speed in such a way as to minimize the error between the measured and estimated currents. Since rotor flux is needed for the stator current estimation in the adaptive model. A rotor flux identifier use VM with value of stator resistor has been update online to enhance the low speed operation performance of the scheme and it also overcome the instability problem in the regenerating mode of operation, this problem occur when using CM for rotor flux identifier. The theoretical analysis is validated by simulink tests of the sensorless-drive system under different operating conditions. Simulation results are given to compare the performance of the proposed obsever with the SC_MRAS observer using CM rotor flux identifier (CM_SC_MRAS) and with the wellknown Rotor flux based (RF) MRAS obsever. Simulink results show the performance has been significantly improved in low-speed operation. Sensorless results also confirm the instability problem not exist in the regenerating-mode low-speed region of operation when using the VM with Rs is identified online for the flux estimation.

This paper is organized into five sections. In Section 2, the basic theory of the modelling of the SPIM and modelling Field Oriented Control FOC for the SPIM drives are presented. Section 3 introduces the proposed NN SC MRAS_observer. Simulation are presented and discussed in Section 4. Finally, the concluding is provided in Section 5.

\section{Model vector control of SPIM drives}

\subsection{Model vector control of SPIM drives}

The system under study consists of an SPIM fed by a six-phase Voltage Source Inverter (VSI) and a DC link. A detailed scheme of the drive is provided in Fig.1. This six-phase machine is a continuous system which can be described by a set of differential equations. The model of the system can be simplified by means of the Vector Space Decomposition (VSD) introduced in [18]. By applying this technique, the original six-dimensional space of the machine is transformed into 


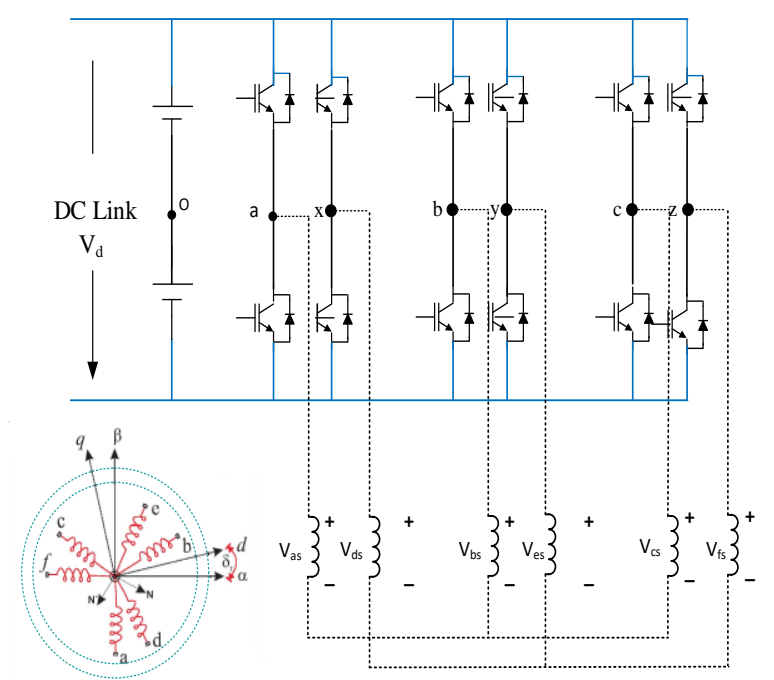

Figure. 1 A general scheme of an SPIM drive
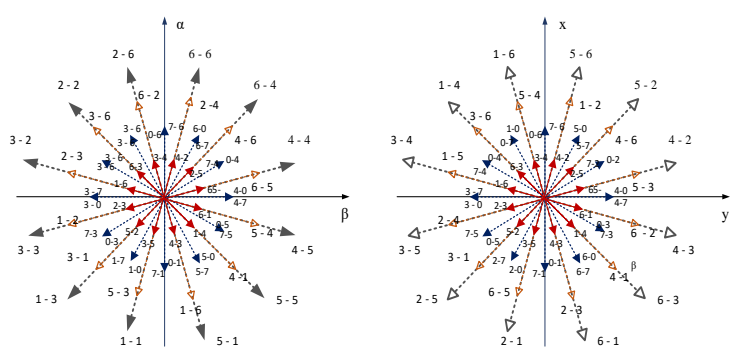

Figure. 2 Voltage space vectors and switching states in the $(\alpha-\beta)$ and $(x-y)$ subspaces for a six-phase VSI

three two-dimensional orthogonal subspaces in the stationary reference frame $(\alpha-\beta),(x-y)$ and (zl -z2). This transformation is obtained by means of $6 \times 6$ transformation matrix:

$$
T_{6}=\left[\begin{array}{cccccc}
1 & \frac{\sqrt{3}}{2} & -\frac{1}{2} & -\frac{\sqrt{3}}{2} & -\frac{1}{2} & 0 \\
0 & \frac{1}{2} & \frac{\sqrt{3}}{2} & \frac{1}{2} & -\frac{\sqrt{3}}{2} & -1 \\
1 & -\frac{\sqrt{3}}{2} & -\frac{1}{2} & \frac{\sqrt{3}}{2} & -\frac{1}{2} & 0 \\
0 & \frac{1}{2} & -\frac{\sqrt{3}}{2} & \frac{1}{2} & \frac{\sqrt{3}}{2} & -1 \\
1 & 0 & 1 & 0 & 1 & 0 \\
0 & 1 & 0 & 1 & 0 & 1
\end{array}\right]
$$

In that, an amplitude invariant criterion was used. From the motor model obtained by using VSD approach, the following conclusions should be emphasized:

1. The electromechanical energy conversion variables are mapped to the $(\alpha-\beta)$ subspace. The non-electromechanical energy conversion variables can be found in other subspaces.
2. The current components in the (x-y) subspace do not contribute to the air gap flux so they should be controlled to be as small as possible.

3. The voltage vectors in the ( $\mathrm{zl}-\mathrm{z} 2)$ are zero due to the separated neutrals configuration of the machine.

A VSI has a discrete nature, actually, it has a total number of $\mathbf{2}^{\mathbf{6}}=64$ different switching states defined by six switching functions corresponding to the six inverter legs [Sa,Sx,Sb,Sy,Sc,Sz], where Si $\mathrm{S}$ $\{0,1\}$. On the other hand, a transformation matrix must be used to represent the stationary reference fame $(\alpha-\beta)$ in the dynamic reference $(d-q)$. This matrix is given:

$$
T_{d q}=\left[\begin{array}{cc}
\cos \left(\delta_{r}\right) & -\sin \left(\delta_{r}\right) \\
\sin \left(\delta_{r}\right) & \cos \left(\delta_{r}\right)
\end{array}\right]
$$

where $\delta_{r}$ is the rotor angular position referred to the stator as shown in Fig. 1. The different switching states and the voltage of the DC link define the phase voltages which can in turn be mapped to the $(\alpha-\beta)-(x-y)$ space according to VSD approach.

\subsection{Model of SPI}

In this part a six phase induction motor, which contains two sets of three phase winding spatially shifed by 30 electrical degrees with isolated neutral points (as depicted in Fig. 1), is modeled. Stator and rotor voltage equation for this model is as follows:

$$
\begin{aligned}
& {\left[V_{s}\right]=\left[R_{s}\right]\left[I_{s}\right]+P\left(\left[L_{s}\right]\left[I_{s}\right]+[M]\left[I_{r}\right]\right.} \\
& {\left[V_{r}\right]=\left[R_{r}\right]\left[I_{r}\right]+P\left(\left[L_{r}\right]\left[I_{r}\right]+[M]\left[I_{s}\right]\right.}
\end{aligned}
$$

Where: respectively, $[V],[I],[R],[L]$ and $[M]$ are voltage, current, resistant, self and mutual inductance vectors. As these equations implies, the electromechanical conversion, only takes place in the $\alpha-\beta$ subspace and the other subspaces just produce losses. So the torque equation can be written as follows:

$$
\begin{aligned}
& T_{e}=3 P\left(\psi_{r Q} i_{r D}-\psi_{r D} i_{r Q}\right) \\
& j_{i} \frac{d}{d t} \omega_{r}+B_{i} \omega_{r}=P\left(T_{e}-T_{L}\right)
\end{aligned}
$$

where: respectively, $J_{i}, \omega_{r}, B_{i}, T_{e}, T_{L} P, \Psi_{r D}, \Psi_{r Q}, i_{r D}$, $i_{r Q}$ are inertia coefficient, angular speed, fiction factor, the electromagnetic torque that generated by the motor, load torque, number of pairs of poles, the 
rotor flux, rotor current, respectively.

\section{SC_MRAS speed observer using NN}

\subsection{SC_MRAS observer using NN}

The SC_MRAS observer has a structure diagram as shown in Fig. 3, which consists of a reference model, an adaptive model, and an adaptation mechanism for estimating speed. In the proposed observer, SPIM itself acts as a reference model. The reference components of the NN SC_MRAS observer are the measured stator current components. The adaptive model can be calculated from the combined voltage and current models (VM and CM) [19] and is described by the following equation:

$$
\begin{aligned}
& T_{n} \frac{d i_{s D}}{d t}=\left(1+\frac{x_{m}^{2}}{x_{r}^{2}}\right) \frac{r_{s}}{x_{s} \sigma} i_{s D}+\frac{1}{x_{s} \sigma} u_{s D}+\frac{1}{x_{s} \sigma} \frac{r_{r} x_{m}}{x_{r}^{2}} \psi_{r D}+\frac{1}{x_{s} \sigma} \frac{x_{m}}{x_{r}} \omega \psi_{r Q} \\
& T_{n} \frac{d i_{s Q}}{d t}=\left(1+\frac{x_{m}^{2}}{x_{r}^{2}}\right) \frac{r_{s}}{x_{s} \sigma} i_{s Q}+\frac{1}{x_{s} \sigma} u_{s Q}+\frac{1}{x_{s} \sigma} \frac{r_{r} x_{m}}{x_{r}^{2}} \psi_{r Q}+\frac{1}{x_{s} \sigma} \frac{x_{m}}{x_{r}} \omega \psi_{r D}
\end{aligned}
$$

where: $\mathrm{u}_{s \mathrm{DQ}}, \mathrm{i}_{s \mathrm{DQ}}, \Psi_{\mathrm{rDQ}}$ are stator voltage, current and rotor flux linkage components in the stationary reference frame, respectively. $r_{s}, r_{r}$ : respectively, stator and rotor resistances, $\mathrm{x}_{\mathrm{s}} ; \mathrm{x}_{\mathrm{r}} ; \mathrm{x}_{\mathrm{m}}$ : respectively stator, rotor reactances and magnetizing, $\mathrm{p}=\mathrm{d} / \mathrm{dt}$ is the differential operator; $\mathrm{T}_{\mathrm{n}}=1 / 2 \pi \mathrm{f}_{\mathrm{sn}} ; \mathrm{f}_{\mathrm{sn}}$ : nominal frequency; $\sigma=1-\mathrm{x}_{\mathrm{m}}^{2} / \mathrm{x}_{\mathrm{s}} \mathrm{x}_{\mathrm{r} \text { : }}$ is the leakage coefficient of the machine.

Eq. (6), Then they been divided by $\mathrm{Tn}$, be re written in the following as:

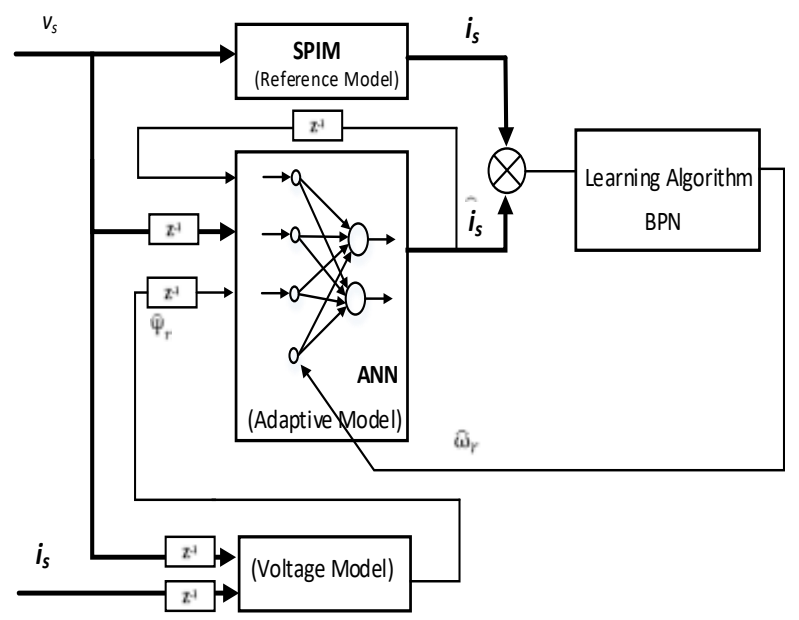

Figure. 3 NNVM_SC_MRAS speed observer

$$
i_{s}=A_{x} i_{s}+B_{x} u_{s}
$$

where:

$$
\begin{aligned}
& i_{s}=\left[\begin{array}{l}
i_{s D} \\
i_{s Q}
\end{array}\right] ; A_{x}=\left[\begin{array}{c}
-\left(1+\frac{x_{m}^{2}}{x_{r}^{2}}\right) \frac{r_{s}}{x_{s} \sigma} \\
-\left(1+\frac{x_{m}^{2}}{x_{r}^{2}}\right) \frac{r_{s}}{x_{s} \sigma}
\end{array}\right] ; \\
& B_{x}=\left[\begin{array}{lllll}
\frac{1}{x_{s} \sigma} & 0 & \frac{1}{x_{s} \sigma} \frac{r_{r} x_{m}}{x_{r}^{2}} & \frac{1}{x_{s} \sigma} \frac{\omega_{r} x_{m}}{x_{r}^{2}} \\
0 & \frac{1}{x_{s} \sigma} & \frac{1}{x_{s} \sigma} \frac{\omega_{r} x_{m}}{x_{r}^{2}} & -\frac{1}{x_{s} \sigma} & \frac{r_{r} x_{m}}{x_{r}^{2}}
\end{array}\right] ; u_{s}=\left[\begin{array}{l}
u_{s Q} \\
u_{s Q} \\
\psi_{, D} \\
\psi_{, Q}
\end{array}\right]
\end{aligned}
$$

Its corresponding discrete model is, therefore, given by:

$$
\hat{i}_{(k)}=e^{A_{x} T_{s}} i_{(k)}+\left[e^{A_{x} T_{s}}-I\right] A_{x}^{-1} B_{x} u_{s(k-1)}
$$

$\mathrm{e}^{\text {AxTs}}$ : is generally computed by truncating its power series expansion

$$
e^{A_{x} T_{s}}=I+\frac{A_{x} T_{s}}{1 !}+\frac{A_{x}^{2} T_{s}}{2 !}+\ldots+\frac{A_{x}^{n} T_{s}}{n !}
$$

If $n=1$, the simple forward Euler method is obtained, which gives the following finite difference equation:

$$
\begin{aligned}
& \hat{i}_{s D}(k)=w_{1} \hat{i}_{s D}(k-1)+w_{2} u_{s D}(k-1)+w_{3} \hat{\psi}_{r Q}(k-1)+w_{4} \hat{\psi}_{r D}(k-1) \\
& \hat{i}_{s Q}(k)=w_{1} \hat{i}_{s Q}(k-1)+w_{2} u_{s Q}(k-1)+w_{3} \hat{\psi}_{r D}(k-1)+w_{4} \hat{\psi}_{r Q}(k-1)
\end{aligned}
$$

where :

$$
w_{1}=1-\frac{T_{s} r_{s}}{\sigma L_{s}}-\frac{T_{s} L_{m}^{2}}{\sigma L_{s} L_{r} T_{r}} ; w_{2}=\frac{T_{s}}{\sigma L_{s}} ; w_{3}=\frac{T_{s} L_{m}}{\sigma L_{s} T_{r}} ; w_{4}=\frac{T_{s} L_{m} \omega_{r}}{\sigma L_{s} L_{r}}
$$

where: $i_{(\mathrm{k})}$ the current variables estimated with the adaptive model and $\mathrm{k}$ is the current time sample, $r_{s}$, $L_{s}, L_{r}, L_{m}$ are stator resistance and stator, rotor, magnetizing inductances, respectively. An Artificial Neural Network (ANN) can reproduce these equations, where $\mathrm{w}_{1}, \mathrm{w}_{2}, \mathrm{w}_{3}, \mathrm{w}_{4}$ are the weights of the neural networks defined as (11); $\mathrm{T}_{\mathrm{s}}$ is the sampling time for the stator current observer. 

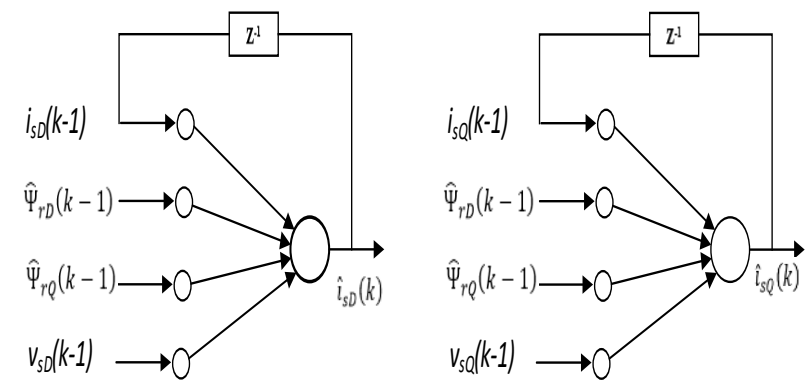

Figure. 4 NN VM SC_MRAS based observer: (a) $\alpha$ axis and (b) $\beta$-axis

A two layer linear $\mathrm{NN}$, that with weights as defined as shown in Fig. 4, can represent Eq. (10) and represent the adaptive model for the SC_ MRAS scheme where $\mathrm{w}_{1}$ and $\mathrm{w}_{4}$, which contain $\mathrm{r}_{\mathrm{s}}$ and the rotor speed information respectively, are adjusted online in such a way as to minimize the error between actual and estimated currents. Since rotor flux estimation is required for the SC_ MRAS scheme, a VM and CM flux observers can be used. In this proposal observer, rotor flux has estimated by VM. The block diagram of the NN-based stator current MRAS scheme using a VM rotor flux observer is shown in Fig. 5. The performance of VM rotor flux observer has been improved significantly with Rs value updated online.

\subsection{Rotor speed estimation algorithm}

In onder to derive the weight adjustment law of the NN stator current observer, define the energy function $\mathrm{E}$ to be minimised:

$$
E=\frac{1}{2} \varepsilon_{i}^{2}(k)
$$

where :

$$
\begin{aligned}
& \varepsilon_{i}(k)=i_{s}(k)-\hat{i}_{s}(k)=\left[i_{s D}(k)-\hat{i}_{s D}(k) \quad i_{s Q}(k)-\hat{i}_{s Q}(k)\right] \\
& =\left[\begin{array}{ll}
\varepsilon_{i D}(k) & \varepsilon_{i Q}(k)
\end{array}\right]^{T}
\end{aligned}
$$

The weight adjustment has to be proportional to the negative of the error gradient to obtain a minimum squared error between actual and estimated stator current.

$$
\frac{\partial E}{\partial w_{4}}=\frac{\partial E}{\partial \hat{i}_{s}(k)} \frac{\partial \hat{i}_{s}(k)}{\partial w_{4}}
$$

$$
\begin{aligned}
& \frac{\partial E}{\partial \hat{i}_{s}(k)}=\frac{1}{2} \frac{\partial}{\partial \hat{i}_{s}(k)}\left[i_{s}(k)-\hat{i}_{s}(k)\right]^{2}=-\varepsilon_{i}^{T}(k) \\
& \frac{\partial \hat{i}_{s}(k)}{\partial w_{4}}=\left[\begin{array}{ll}
\hat{\psi}_{r Q}(k-1) & -\hat{\psi}_{r D}(k-1)
\end{array}\right]^{T}
\end{aligned}
$$

Substituting (15) and (16) into (14) :

$$
-\frac{\partial E}{\partial w_{4}}=\varepsilon_{i D}(k) \hat{\psi}_{r Q}(k-1)-\varepsilon_{i Q}(k) \hat{\psi}_{r D}(k-1)
$$

The weight adjustment law of the NN_VM_SC_ MRAS observer can be derived based on backpropagation network (BPN) algorithm and can be written:

$$
\begin{aligned}
\Delta w_{4}(k) & =-\eta \frac{\partial E}{\partial w_{4}} \\
& =-\eta\left[\varepsilon_{i s D}(k) \hat{\psi}_{r Q}(k-1)-\varepsilon_{i s Q}(k) \hat{\psi}_{r D}(k-1)\right]
\end{aligned}
$$

where $\eta$ is a positive constant called the learning rate. Hence the weight update equation:

$$
w_{4}(k)=w_{4}(k-1)+\Delta w_{4}(k)+\alpha \Delta w_{4}(k)
$$

where $\alpha$ is a positive constant called the momentum constant. Due to simple structure of the NN stator current observer, the weight adjustment can be performed online and the motor speed can be estimated from the weight $\mathrm{w}_{4}$ as:

$$
\hat{\omega}_{r}(k)=\frac{\sigma L_{s} L_{r}}{T_{s} L_{m}} w_{4}(k)
$$

\subsection{Rotor flux estimation and stator resistance online estimation algorithm}

From the analysis of the model can been seen that, the adaptive model generates stator current estimation values based on rotor speed information, stator voltages and rotor flux. From Eq. (10) represents the stator current observer, we see that the rotor flux is required to calculate the estimated stator current. The reference model, usually expressed as a $\mathrm{VM}$, represents the stator equation and can be written as follows:

where: 


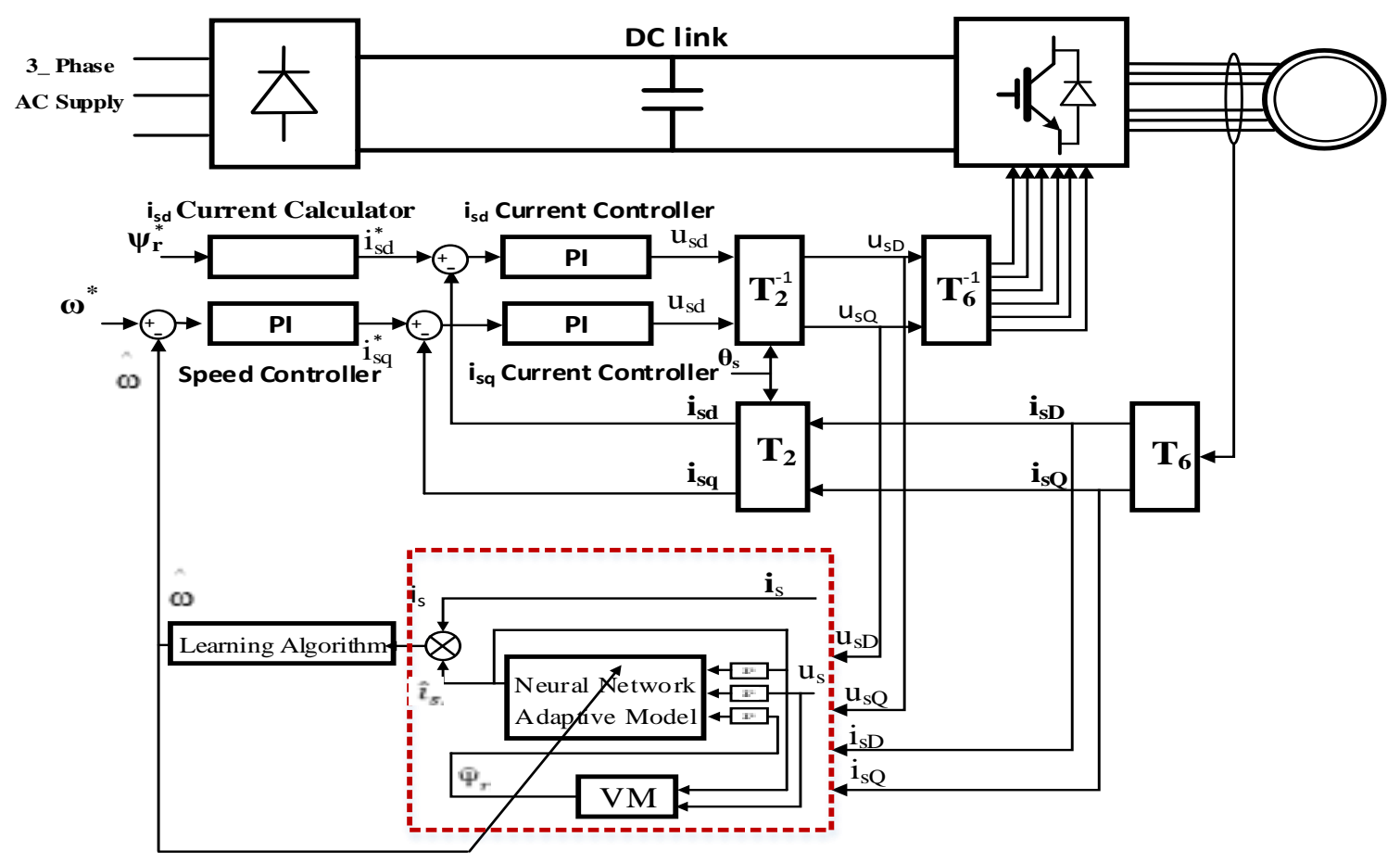

Figure. 5 Sensorless vector control of SPIM drive using NN_SC_MRAS observer

$$
\begin{aligned}
& \frac{d \psi_{r D}}{d t}=\frac{x_{r}}{x_{m}}\left(v_{s D}-R_{s} i_{s D}-\sigma T_{n} x_{s} p i_{s D}\right) \\
& \frac{d \psi_{r Q}}{d t}=\frac{x_{r}}{x_{m}}\left(v_{s Q}-R_{s} i_{s Q}-\sigma T_{n} x_{s} p i_{s Q}\right)
\end{aligned}
$$

In this proposed observer, the rotor flux components are identified base on Eq. (21) (VM) to generate the estimated rotor flux value what are provided for the adaptive model of the proposed observer. These rotor flux components are identified from the control voltage and the measured stator current. Using this VM will overcome the instability problem in the regenerating mode of operation using current model. However, VM is influence with the motor parameter variation so that to improve the performance of the observer at low speed. From Eqs. (10), (11), (12) to minimize squared error between actual and estimated stator current the weight adjustment has to be proportional to the negative of the error gradient with respect to the weight. It can be written as:

$$
w_{1}(k)=w_{1}(k-1)+\Delta w_{1}(k)+\gamma \Delta w_{1}(k)
$$

where

$$
\begin{aligned}
\Delta w_{1}(k) & =-\beta \frac{\partial E}{\partial w_{1}} \\
& =-\beta\left[\varepsilon_{i s D}(k) \hat{i}_{s D}(k-1)+\varepsilon_{i s Q}(k) \hat{i}_{s Q}(k-1)\right]
\end{aligned}
$$

where $\gamma$ is a positive constant called the momentum constant, $\beta$ is a positive constant called the learning rate. Due to simple structure of the NN stator current observer, the weight adjustment can be performed online and the stator resistance can be estimated from the weight w1 as:

$$
\hat{R}_{s}(k+1)=\frac{\sigma L_{s}}{T_{s}}\left[1-\frac{T_{s} L_{m}^{2}}{\sigma L_{r} L_{s} T_{r}}-w_{1}(k+1)\right]
$$

\section{Simulink and discussion}

In order to verify and evaluate the performance of the SC_MRAS using NN observer a sensorless vector control of SPIM drive system, as shown in Fig. 6 has been simulated at different speed ranges through Matlab simulation software, specially surveyed at low speed range. Tests in this section are conducted based on recommended benchmark tests $[17,21,22]$. SPIM parameters: $1 \mathrm{HP}, 220 \mathrm{~V}, 50$ $\mathrm{Hz}, 4$ pole, $1450 \mathrm{rpm} . \mathrm{Rs}=10.1 \Omega, \mathrm{Rr}=9.8546 \Omega$, $\mathrm{Ls}=0.833457 \mathrm{H}, \mathrm{Lr}=0.830811 \mathrm{H}, \mathrm{m}=0.783106 \mathrm{H}$, 
$\mathrm{Ji}=0.0088 \mathrm{~kg} \cdot \mathrm{m} 2 . \mathrm{Rs}$ is nominal value of stator resistance.

\subsection{Sensitivity to stator resistance variation}

The purpose of this test is to verify the speed estimation performance of the MRAS observers for motor parameter variation. The drive and observer have been verified by increasing $30 \%$ Rs at $t=3 \mathrm{~s}$, the reference speed has been keep constantly $90(\mathrm{rad} / \mathrm{s})$ during the survey time at no load and 55\% load torque applied at $\mathrm{t}=1.75 \mathrm{~s}$.

Figs. 6 (a) and (b) show that RF_MRAS observer works not reliably, low performance, large amplitude of oscillation and unstable when Rs increase. This result is consistent with the analysis in sections 3. With RF_MRAS observer, VM contains the stator resistance Rs so that when Rs change the rotor flux, which is identified from VM, is incorrectly with the rotor flux identified from CM. This made the error between the actual speed and the Estimated speed is rising and instability.In contrast, for the NN_SC MRAS observer the speed and torque responses of the drive using proposal observer are very quick well, the speed estimation error is small, after few oscillations the estimated speed converges to the reference value and real speed. The VM based rotor flux identifier with Rs value updated online is quite accurate, which then provided to the adaptive stator current estimator. The use of the VM solves the instability problem of the regeneration mode and ensures the performance of the speed observer when updated online Rs value Figs. 7 (a) and (b). To making clearer the effectiveness of the proposed observer, another survey also is conducted in case the motor parameter variation based on recommended in [21].

Fig. 8 shows the performance of the observer when Rs variations (Rs is increased $20 \%$ at $4.5 \mathrm{~s}$ and $85 \%$ load is applied at $6 \mathrm{~s}$ ). The reference speed is changed from $20 \mathrm{rad} / \mathrm{s}$ to zero, $6.5 \mathrm{rad} / \mathrm{s}$ steps. The stable operation and oscillating speed performance of the proposed SC_MRAS observer and proposed observer in [21] (Fig. 10) obtained are quite good. As we know that the stator resistance variation with temperature, which can be up to $50 \%$, is a very serious problem at low speed. Since the fundamental component of the stator voltage becomes very low, the stator resistance drop becomes comparable to the applied voltage. Hence continuous adaptation of the stator resistance is required to maintain stable operation at low speed [20]. However, the performance of the observer with the Rs variation increased more than $20 \%$ and the lower speed operation ranges were not shown in [21].

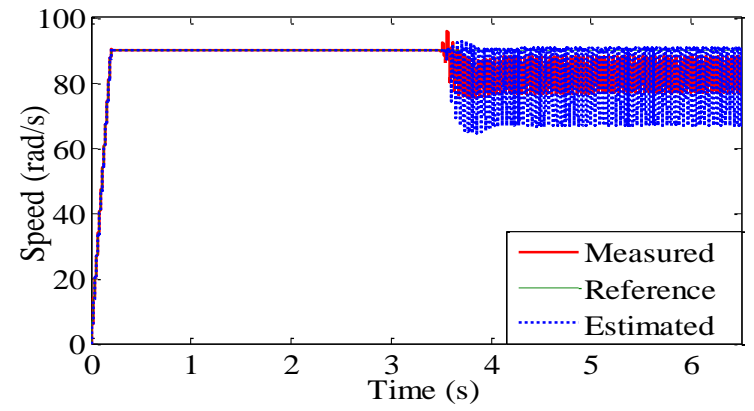

(a)

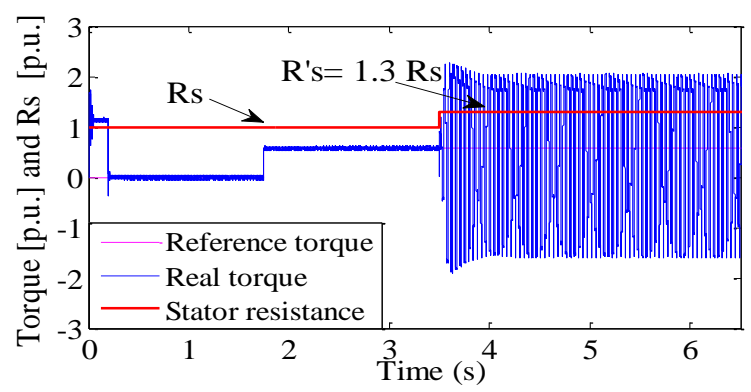

(b)

Figure. 6 RF_MRAS observer when load torque and resistance variation: (a) speed responses and (b) load torque and resistance

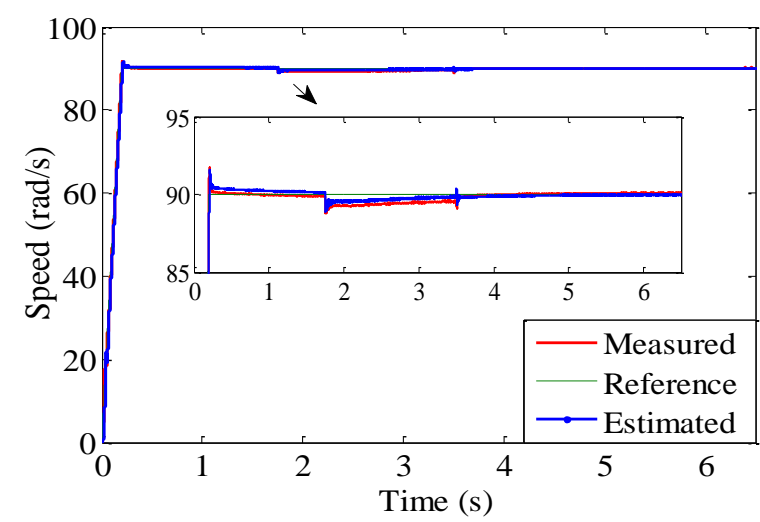

(a)

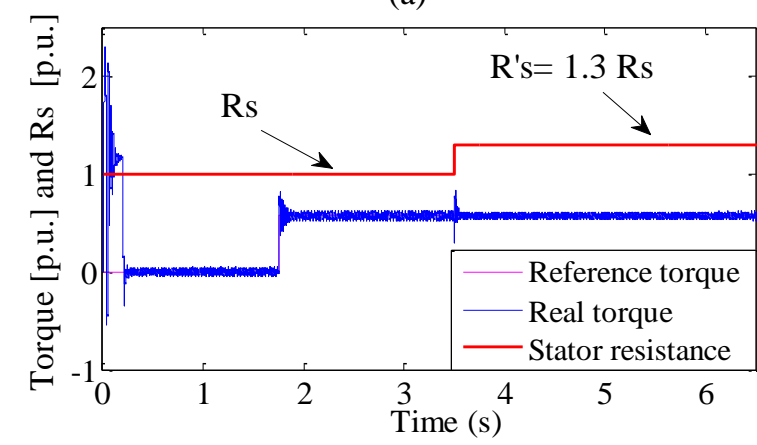

(b)

Figure. 7 NNVMSC__MRAS observer when load torque and resistance variation: (a) speed responses and (b) load torque and resistance 

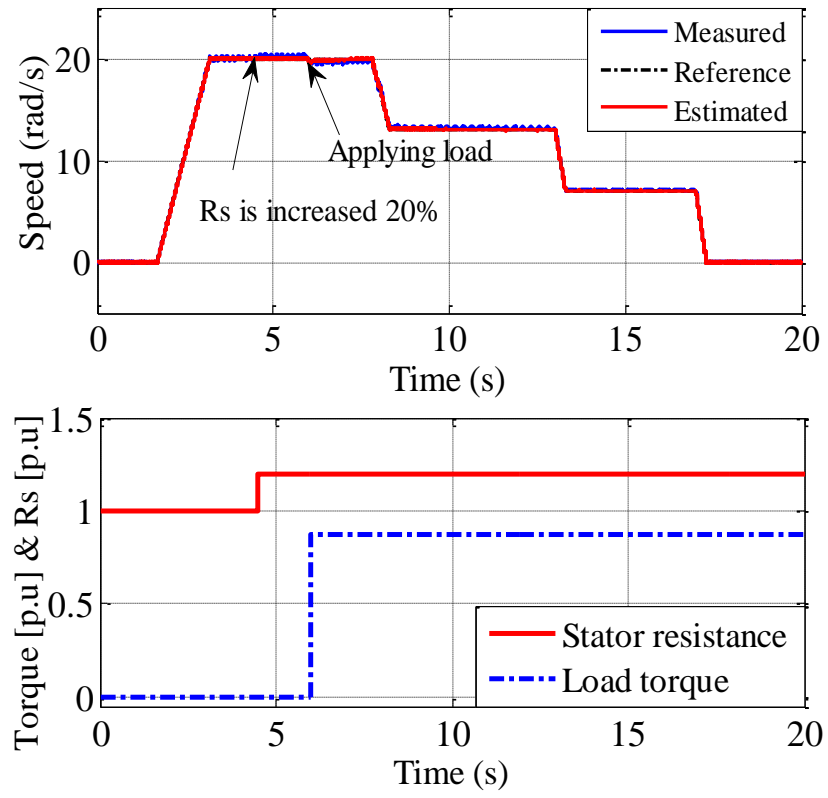

Figure. 8 The proposed SCMRAS observer for load torque and Rs variations: Speed responses and Load torque, stator resistance.
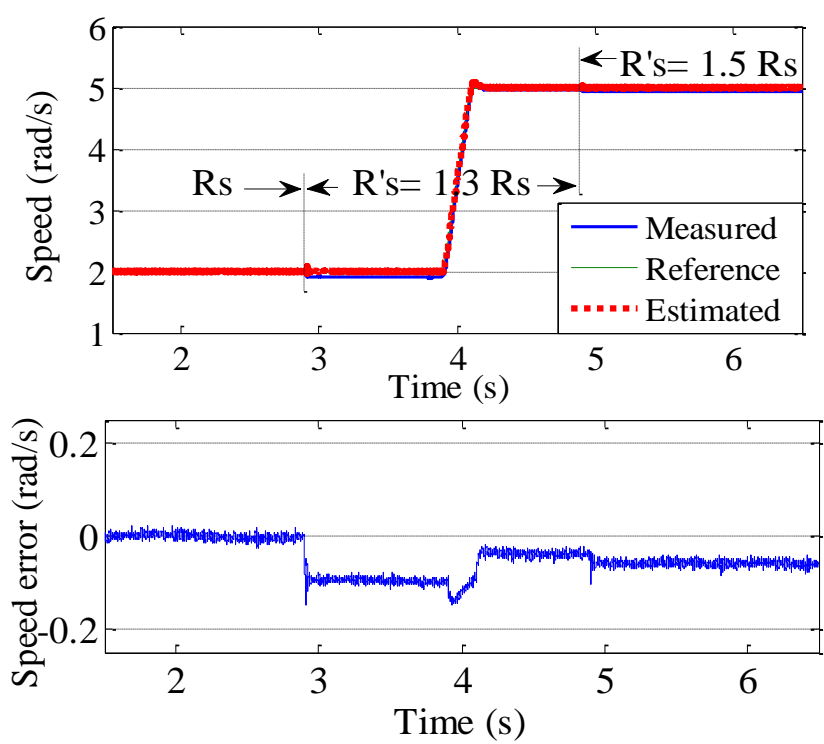

Figure. 9 Speed responses and estimation error NN_SC_MRAS observer when has Rs variations

In this research, the lower reference speed range was also set-up. The speed has been changed from 2 $\mathrm{rad} / \mathrm{s}$ to $5 \mathrm{rad} / \mathrm{s}$, Rs increase from $30 \%$ to $50 \%$ at $2.9 \mathrm{~s}$ and $4.9 \mathrm{~s}$, respectively. The results in Fig. 9 show the drive and proposed observer still work well and stably even if Rs increase 50\%. The speed error is quite low, increase higher a little in low speed region.
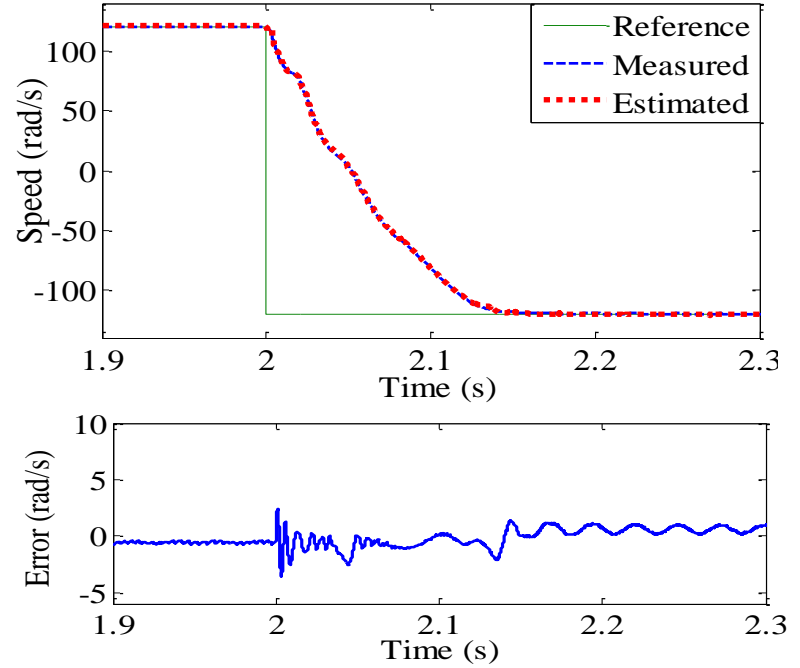

Figure. 10 Speed responses during reversal and speed error of the NN_VM_SC_MRAS observer
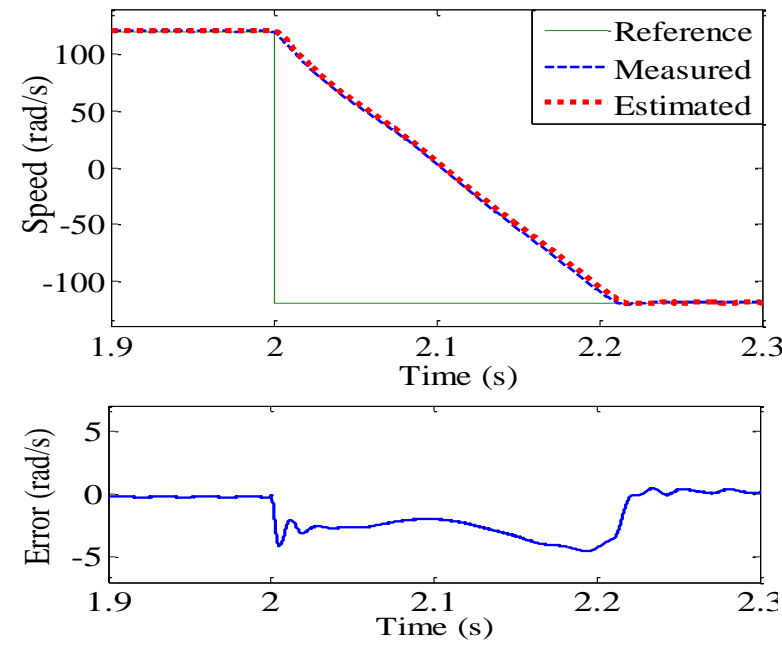

Figure. 11 Speed responses during reversal and speed error of the CM_SC_MRAS observer

\subsection{Dynamic performances}

In this second test, the dynamic performance of the drive and observer have been verified by commanding a step speed reversal from $120 \mathrm{rad} / \mathrm{s}$ to $-120 \mathrm{rad} / \mathrm{s}$ with rated load.

Figs. 10 and 11 show the speed responses, speed error and torque during speed reversal. The simulation results show that in both CM_SC_MRAS and the proposed MRAS schemes the speed reversal is accomplished in less than 1s and that the torque response is instantaneous. The speed error is maximum at zero crossing and during the speed transient and it is about $2.3 \mathrm{rad} / \mathrm{s}$ for NN_SC_MRAS observer and $5 \mathrm{rad} / \mathrm{s}$ for CM_SC_MRAS observer. The speed response of NN-SC_MRAS drive is very well (Fig. 10). The speed error is quite low with NN-SC_MRAS 
observer. For the CM_SC_MRAS observer, it oscillates and increases higher, the convergence time of the estimated and measured speed to reference speed value are longer (Fig. 11).

Fig. 12 shows the speed responses of proposed observer during speed reversal +/_50rad/s, 50\%load. These simulation results show that during the speed transient, the estimated speed and the real follow the reference speed very well. It is easy to see that the observer presented in this paper gives results better those of a much more complicated MRAS observer [17] (Fig. 7). The speed estimation error is higher, the performance of observer in [17] during the transient speed is poorer than the proposed observer. Furthermore, a speed reversal from $-10 \mathrm{rad} / \mathrm{s}$ to 10 $\mathrm{rad} / \mathrm{s}$ at $25 \%$ rated load has been performed for testing the dynamic performances of the drive using NNVM-SC_MRAS at low speed. The results in Fig. 13 show the proposed observer is very quick converges, after few oscillations it converges to the reference value.
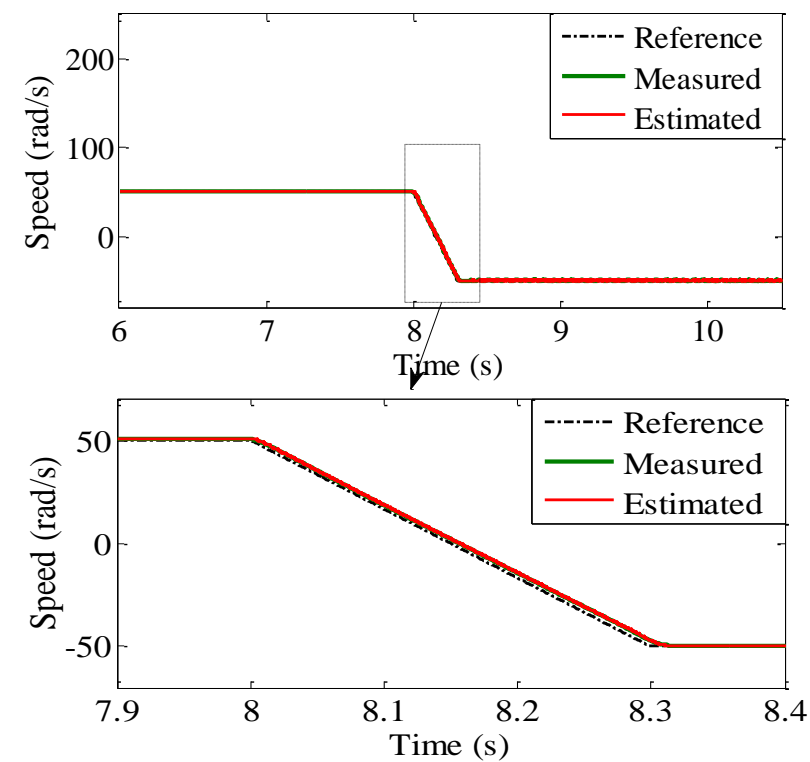

Figure. 12 The speed responses of NNVM_SC_MRAS observer during reversal, +/-50 rad/, $50 \%$ load

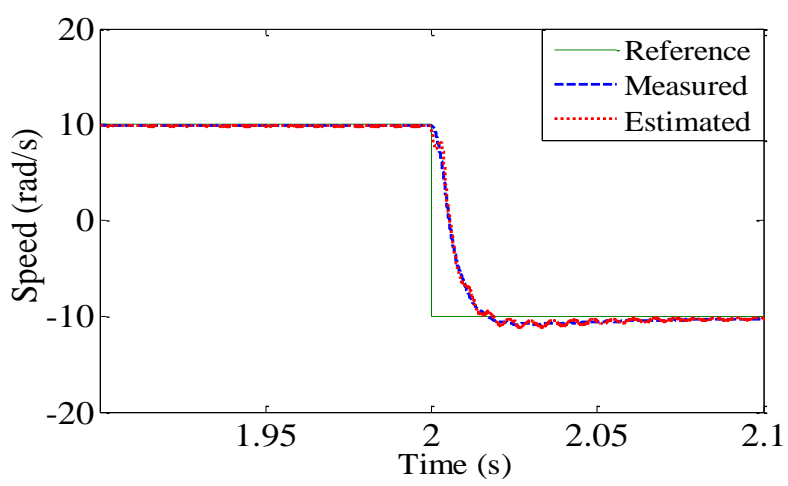

Figure. 13 The speed responses of NNVM_SC_MRAS observer during reversal, +/-10 rad/, $25 \%$ load

\subsection{Medium/Low-speed accuracy}

The performance of the speed estimation was verified by providing different speed reference range from $100 \mathrm{rad} / \mathrm{s}$ to $-20 \mathrm{rad} / \mathrm{s}, 20 \mathrm{rad} / \mathrm{s}$ steps, with $75 \%$ load. This simulation was performed with two sets of observations using NNVM_SC_MRAS and CM_SC_MRAS for comparison, evaluation the performance of both. The Figs. 14 (a) and (b) show

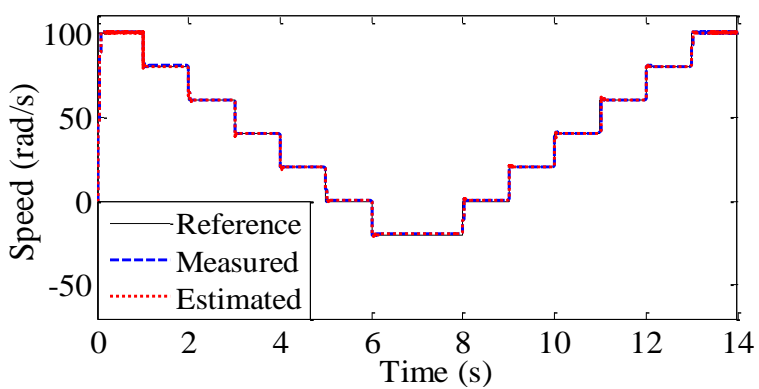

(a)

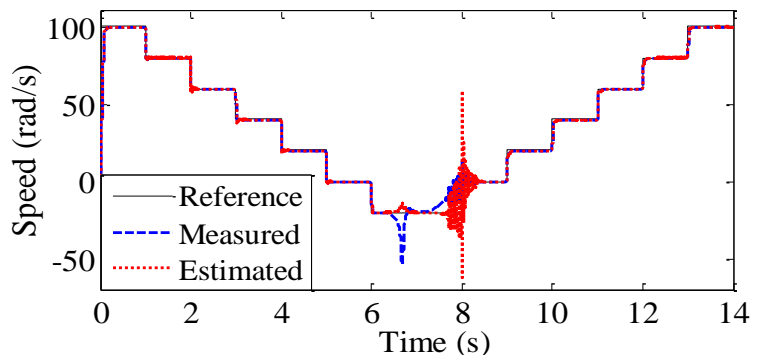

(b)

Figure. 14 Medium/low operation speed region: (a) the proposed MRAS observer and (b) CM SC_MRAS observer
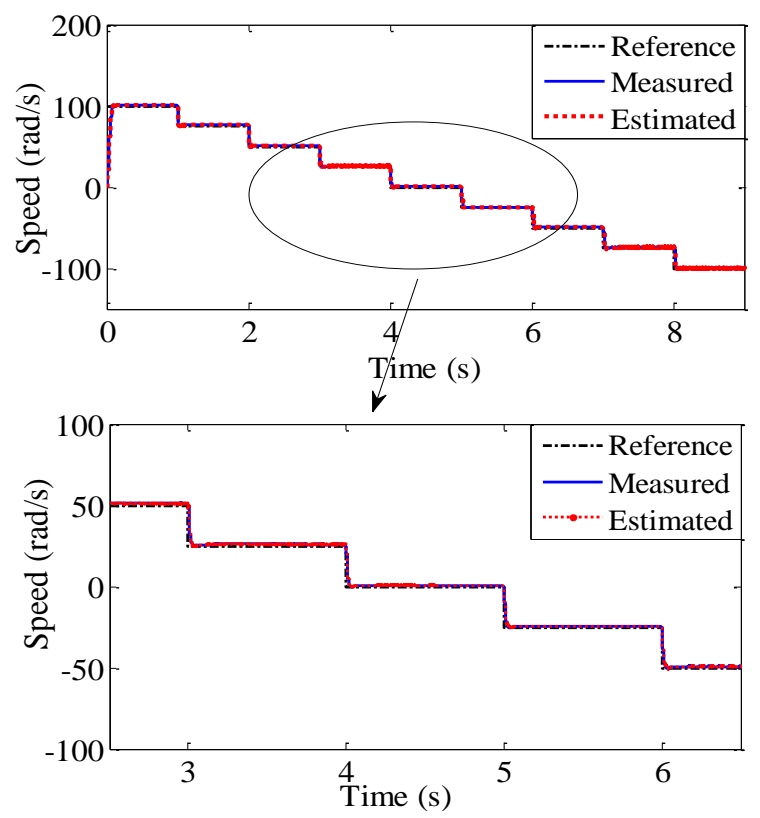

Figure. 15 Speed responses of NN VM_SC_MRAS observer in medium/Low operation speed region 
the reference speed, estimated speed, actual speed of observations based on NN VM_SC_MRAS and CM_SC_MRAS, respectively. These results show that the performance of proposal observer is very good (Fig. 14 (a)). For observer based on CM_SC_MRAS has the poorer performance, especially in the regenerating-mode low-speed region, the speed oscillated with large amplitude, instability (Fig. 14 (b)). Fig. 15 shows the sensorless performance of the proposed speed observer for a speed change from $100 \mathrm{rad} / \mathrm{s}$ to $-100 \mathrm{rad} / \mathrm{s}$ speed at $50 \%$ load is very good. In contrast, the speed estimation error of SC MRAS using NN is proposed in [17] (Figs. 9 (b) and (d)) increase high especially low and zero speed region. In this speed region, unstable operation and oscillating speed also occur.

Another survey also is carried out to justify the effectiveness of the proposed method in the low and zero speed region based on recommended in [22]. Figs. 16 (a) and (b) show the speed responses of proposed SC_MRAS at no load and 50\% load, respectively. In this test the drive has been given a speed reference step of $15 \mathrm{rad} / \mathrm{s}$ to zero to $15 \mathrm{rad} / \mathrm{s}, 3$ $\mathrm{rad} / \mathrm{s}$ steps, $25 \%$ load applied at $2.5 \mathrm{~s}$ and rejected at $15 \mathrm{~s}$. The results in Fig.16 show that no instability phenomena occur at low and zero speed range, the speed estimated error is not significantly. In contrast, with a proposed observer in [22] (Fig. 7, Fig. 8) shows instability phenomena, the estimated error increase at low and zero speed range.

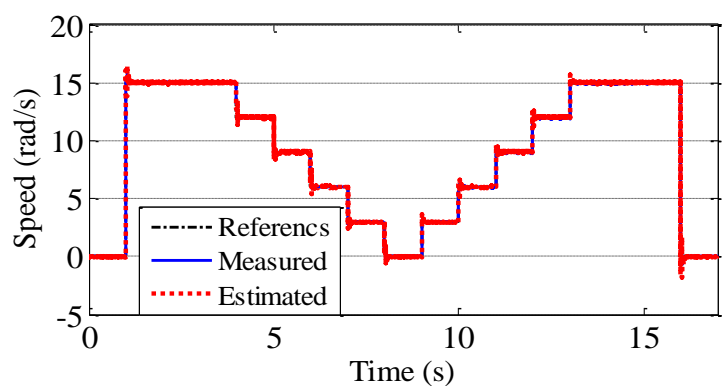

(a)

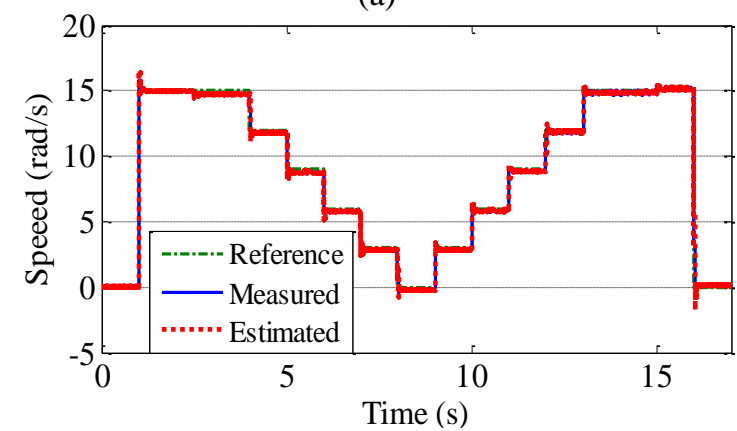

(b)

Figure. 16 Speed responses of NN VM_SC_MRAS observer in two cases: (a) No load and (b) $50 \%$ load

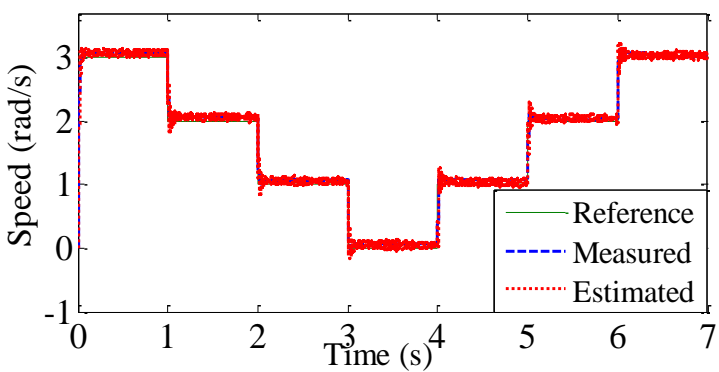

(a)

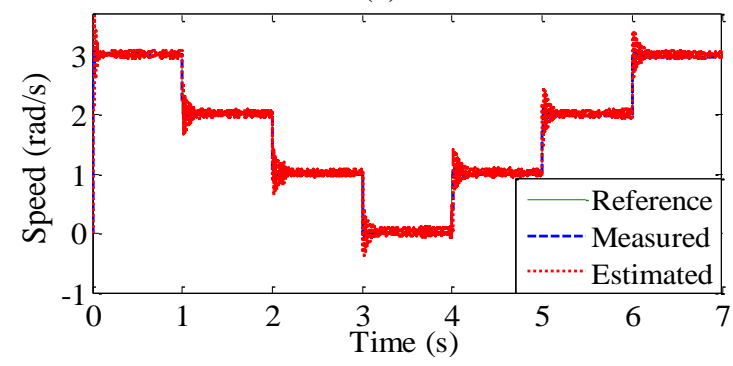

(b)

Figure. 17 The proposed observer in two cases in very low speed range: (a) No load and (b) $12 \%$ rated load

The very low reference speed range was also setup reduced from $3 \mathrm{rad} / \mathrm{s}$ to zero, then increase from zero to $3 \mathrm{rad} / \mathrm{sat}$ no load and $25 \%$ load. The results in Figs. 17 (a) and (b) show that the surveyed speed waveform in both cases is the same, the speed response in the near zero is very good, the performance of observer is very good, the drive and observer work stably. It should be remarked that minimum working speed of the NNVM_SCMRAS observer is lower than that reached in [17, 21, 22], thanks to the improved features of the proposed MRAS scheme.

\subsection{Load perturbations}

In this test, the robustness of the speed estimation of the observer to a sudden torque perturbation has been surveyed. It was carried out to prove the behavior of the proposed scheme when load torque variations. Figs. 18 (a) and (b) show the speed estimation performance for $25 \%, 75 \%$ load disturbance rejection at $20 \mathrm{rad} / \mathrm{s}$ and $80 \mathrm{rad} / \mathrm{s}$ and 30 $\mathrm{rad} / \mathrm{s}$, respectively. The speed responses of the proposed MRAS observer to a variation in load torque and speed for the motoring regions of operation to a speed demand of $20 \mathrm{rad} / \mathrm{s}$ increase to $80 \mathrm{rad} / \mathrm{s}$, then reducing to $30 \mathrm{rad} / \mathrm{s}$, $25 \%$ load applied at $3.5 \mathrm{~s}$, increasing to $75 \%$ load at $7.5 \mathrm{~s}$, and reducing to zero at $12 \mathrm{~s}$ were showed. The proposed SC_MRAS scheme show better transient and steady state performance compared to the proposed observer in [22] (Fig. 9). This is due to the stator current based scheme is not directly affected by 


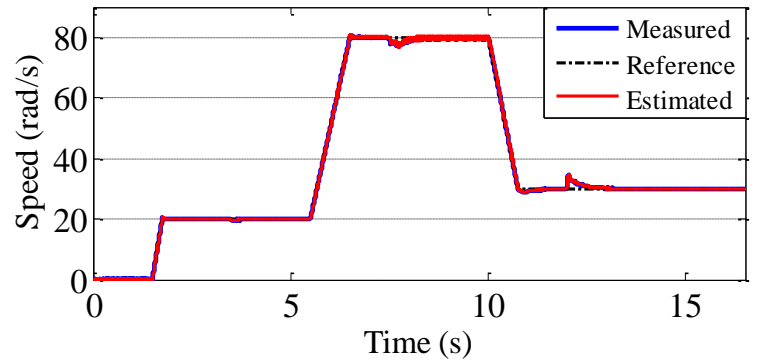

(a)

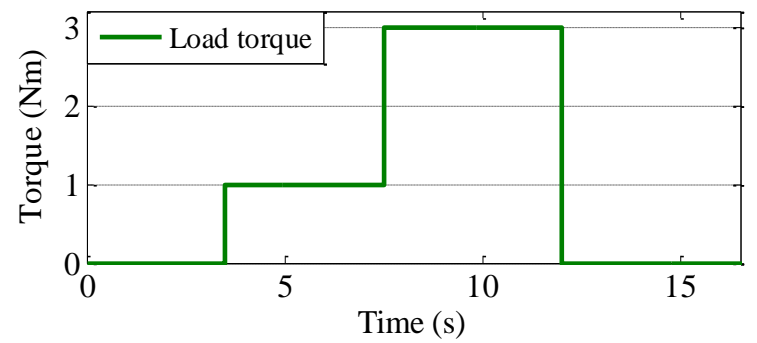

(b)

Figure. 18 The NNM_SC_MRAS observer in case load perturbations: (a) speed responses and (b) load torque

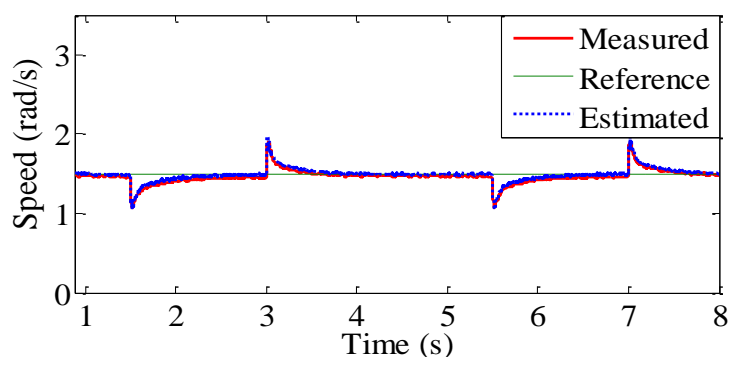

Figure. 19 The speed with $12 \%$ load disturbance rejection of the drive using NNVM_SC_MRAS observer

stator voltage, in contrast, the proposed scheme in [22] for rotor flux estimation is affected by this voltage hence the proposed MRAS scheme have better performance especially.

The behavior of the proposed scheme with the very lower rotor speed was kept constant at $1.5 \mathrm{rad} / \mathrm{s}$, the load torque applied $12 \%$ rated torque at (1.5$3 \mathrm{~s})$ and $(5.5-7 \mathrm{~s})$ is also survey. Fig. 19 shows the reference, measured, and estimated speed, these results show that the speed responses of the drive using the proposed NN SC_MRAS observer occurs immediately when the torque steps are given. Even during the speed transient that caused by the torque step, the estimated speed follows the real speed is very good.

\subsection{The speed in regenerating region}

In this test, speed estimation performance of observer in regenerating mode at low speed region has been surveyed. The load torque in this surveyed case was kept constant at $25 \%$ rated torque with the speed reversal from $20 \mathrm{rad} / \mathrm{s}$ to $-20 \mathrm{rad} / \mathrm{s}$.

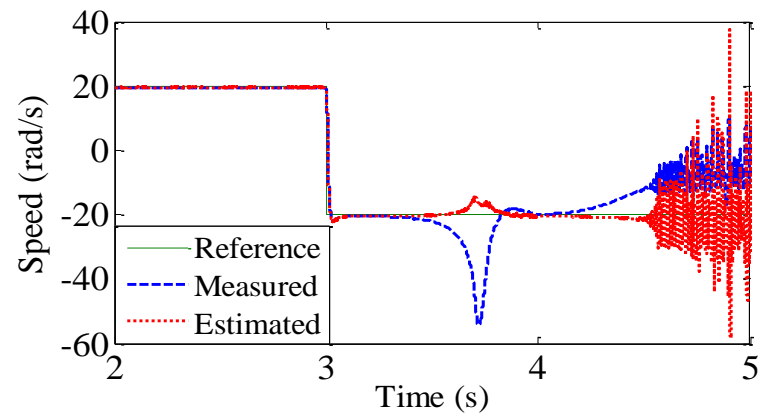

(a)

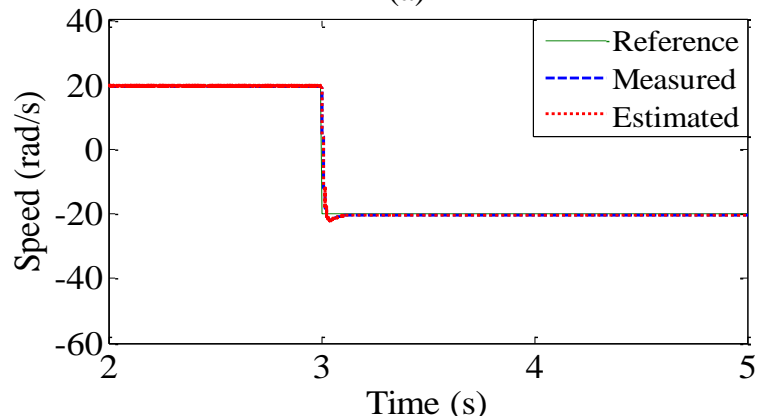

(b)

Figure. 20 Speed estimation performance of: (a) NN VM SC_MRA observer and (b) CM_SC_MRAS observer
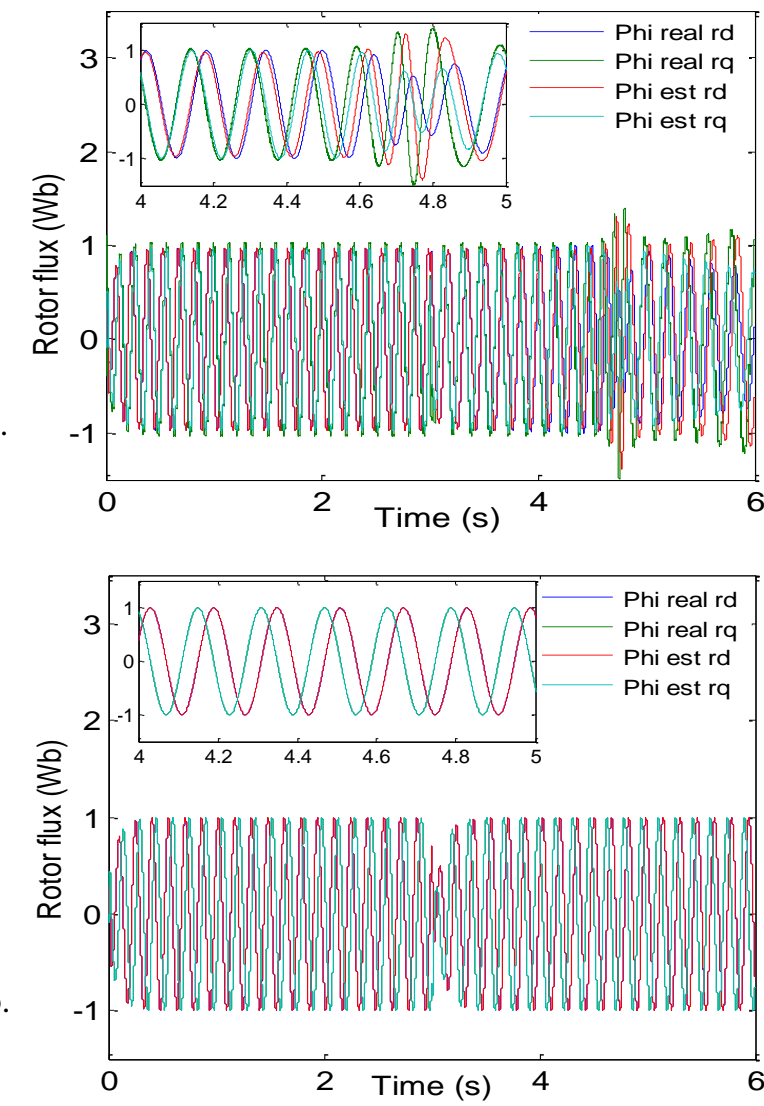

Figure. 21 The real and estimated rotor flux components:

(a) NN_VM_SC_MRAS and (b) CM_SC_MRAS 


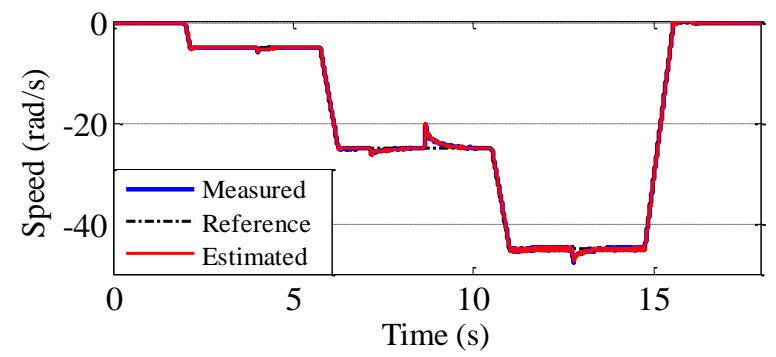

(a)

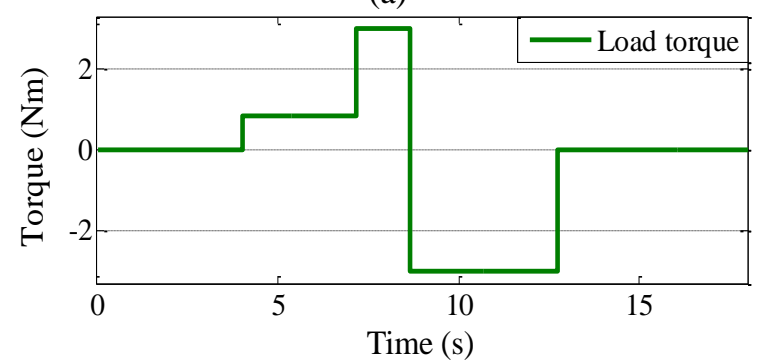

(b)

Figure. 22 The performance of NN VM_SC_MRAS

observer: (a) speed responses and (b) load torque

The CM_SC_MRAS observer, which use CM to estimate the rotor flux, is instability in the regenerating mode at low speed region. In this mode the motor is run in the negative speed region with a positive load torque applied. Since rotor flux estimation using $\mathrm{CM}$ depends on the estimated speed, any deterioration in the speed estimation is fed back to the causing the deterioration of the flux estimation performance (Fig. 21 (a)) and the instability in the regenerating mode of operation Fig. 20 (a). This has been overcome when using VM with Rs is updated online to identify rotor flux, Fig. 20 (b) and Fig. 21 (b) shows a stable performance of rotor flux identifier and speed observer during regeneration mode.

Another survey also carried out to compare between the proposed SC_MRAS observer and the modified torque MRAS observer [22] in regenerating region. The speed changes from zero to $-5 \mathrm{rad} / \mathrm{s}$ to $-25 \mathrm{rad} / \mathrm{s}$ to $-45 \mathrm{rad} / \mathrm{s}$ to 0 for a sequence of external load step changes of 0 to $25 \%$ load at $4 \mathrm{~s}$, up to $75 \%$ load at 7.5 and then reducing to $-75 \%$ load at 8.75 , increasing again to zero at $12.25 \mathrm{~s}$. Fig. 22 shows the speed responses in the negative speed region, with both motoring and regenerative operation mode. Regenerative operation is occurring at $4 \mathrm{~s}$ with $-5 \mathrm{rad} / \mathrm{s}$ and $25 \%$ load, at $7.5 \mathrm{~s}$ with -25 $\mathrm{rad} / \mathrm{s}$ and $75 \%$ load before a load torque reversal from $75 \%$ to- $75 \%$ occurs at $8.75 \mathrm{~s}$. Comparing these results and that obtained in [22] (Figs. 10 (a) and (b)) show both schemes have capability of handling regenerative operation and large load changes are quite well due to rotor flux estimation not using CM depends on the estimated speed. However, the performance of the speed estimation in regenerating region and the transient and steady state performance of the proposed MRAS observer is better with less steady state error especially at low speed regions.

\section{Conclusion}

In this paper, a novel SC_MRAS based scheme using NN for sensorless controlled SPIM drive is presented. From analysis in section 3 and the simulation results in section 4 have shown, on the one hand, the proposed SC_MRAS observer was able to estimate accurately the actual speed at low and zero speed. On the other hand, the robustness of the proposed observer regarding load torque and stator resistance variations and the instability problem not exist in the regenerating mode low speed region of operation. The comparison data in section 4 also have proven that the NNVM_SC_MRAS observer is much better solution those of a complicated observer in $[17,21$, 22] especially, at low and zero speed range. However, using ANN to enhance the performance of the observer will require the computational burden compare to a simple mathematical equation of the conventional observer using $\mathrm{CM}$ and VM, this may impose a drawback of the proposed strategy. Therefore, in order to improve this problem the study other NN structures and algorithms, that require less computational effort, will continue to be developed in future.

\section{References}

[1] E. Levi, "Multiphase Electric Machines for Variable Speed Applications", IEEE Transactions on Industrial Electronics, Vol.55, No.5, pp.1893-1909, 2008.

[2] R. Kianinezhad, B.N. Mobarakeh, L. Baghli, F. Betin, and G. Capolino, "Modeling and Control of Six-Phase Symmetrical Induction Machine Under Fault Condition Due to Open Phases", IEEE Transactions on Industrial Electronics, Vol.55, No.5, pp.1966-1977, 2008.

[3] H. Kubota, K. Matsuse, and T. Nakano, "DspBased Speed Adaptive Flux Observer of Induction Motor", IEEE Transactions on Industry Applications, Vol.29, No.2, pp.344348, 1993.

[4] R.P. Vieira, C.C. Gastaldini, R.Z. Azzolin, and H. A. Grundling, "Discrete-Time Sliding Mode Speed Observer for Sensorless Control of Induction Motor Drives", IET Electric Power Applications, Vol. 6, No.9, pp.681-688, 2012. 
[5] S. Jafarzadeh, C. Lascu, and M.S. Fadali, "State Estimation of Induction Motor Drives Using The Unscented Kalman Filter", IEEE Transactions on Industrial Electronics, Vol.59, No.11, pp.4207-4216, 2012.

[6] C. Schauder, "Adaptive Speed Identification for Vector Control of Induction Motors without Rotational Transducers", IEEE Transactions on Industry Applications, Vol.28, No.5, pp.10541061, 1992.

[7] A.V.R. Teja, C. Chakraborty, S. Maiti, and Y. Hori, "A New Model Reference Adaptive Controller for Four Quadrant Vector Controlled Induction Motor Drives", IEEE Transactions on Industrial Electronics, Vol.59, No.10, pp.3757-3767, 2012.

[8] S. Maiti, V.Verma, C. Chakraborty, and Y. Hori, "An adaptive speed sensorless induction motor drive with artificial neural network for stability enhancement", IEEE Transactions on Industrial Informatics, Vol.8, No.4, pp.757-766, 2012.

[9] Y.B. Zbede, M.S. Gadoue, and D. J. Atkinson, "Model Predictive Mras Estimator For Sensorless Induction Motor Drives", IEEE Transactions on Industrial Electronics, Vol. 63, No.6, pp.3511-3521, 2016.

[10] G. Foo and M.F. Rahman, "Sensorless SlidingMode Mtpa Control of An Ipm Synchronous Motor Drive Using A Sliding-Mode Observer And Hf Signal Injection", IEEE Transactions on Industrial Electronics, Vol.57, No.4, pp.1270-1278, 2010.

[11] O. Keysan and H.B. Ertan, "Real-Time Speed and Position Estimation Using Rotor Slot Harmonics", IEEE Transactions on Industrial Informatics, Vol.9, No.2, pp.899-908, 2013.

[12] C. Schauder, "Adaptive Speed Identification for Vector Control of Induction Motors without Rotational Transducers", IEEE Transactions on Industry Applications, Vol. 28, No. 5, pp.10541061, 1992.

[13] M. Rashed and A.F. Stronach, "A Stable BackEmf Mras-Based Sensorless Low Speed Induction Motor Drive Insensitive to Stato Resistance Variation", In: Proc. of Electric Power Applications, Vol.151, No. 6, pp. 685693, 2004.

[14] F.Z. Peng and T. Fukao, "Robust Speed Identification for Speed-Sensorless Vector Control of Induction Motors", IEEE Transactions on Industry Applications, Vol.30, No.5, pp.1234-1240, 1994.

[15] S.M. Gadoue, D. Giaouris, and J.W. Finch, "A Neural Network Based Stator Current Mras
Observer for Speed Sensorless Induction Motor Drives", In: Proc. of IEEE International Symposium on Industrial, pp.650-655, 2008.

[16] S.M. Gadoue, D. Giaouris, and J.W. Finch, "An Experimental Assessment of A Stator Current Mras Based on Neural Networks for Sensorless Control of Induction Machines", In: Proc. of Symposium on Sensorless Control for Electrical Drives, pp.102-106, 2011.

[17] S.M. Gadoue, D. Giaouris, and J.W. Finch, "Stator Current Model Reference Adaptive Systems Speed Estimator For RegeneratingMode Low-Speed Operation Of Sensorless Induction Motor Drives", IET Electric Power Applications, Vol.7, No.7, pp.597-606, 2013.

[18] Y. Zhao and T. A. Lipo, "Space vector PWM control of dual three-phase induction machine using vector space decomposition", IEEE Trans. Ind. Appl., Vol.31, No.5, pp.1100-1109, 1995.

[19] P. Vas, Sensorless Vector and Direct Torque Control, Oxford University Press, New York, 1998.

[20] R.B. Gimenez, G. M. Asher, M. Sumner, and K.L. Bradley, "Dynamic performance limitations for MRAS based sensorless induction motor drives. Part2: Online parameter tuning and dynamic performance studies", In: IEE Proc. of Electric Power Applications, Vol.143, No.2, pp.123-134, 1996.

[21] I. Benlaloui, S. Drid, L.C. Alaoui, and M. Ouriagli, "Implementation of a New MRAS Speed Sensorless Vector Control of Induction Machine", IEEE Transactions on Energy Conversion, Vol.30, No.2, pp.588 - 595, 2015.

[22] A. N. Smith, S.M. Gadoue, and J.W. Finch, "Improved Rotor Flux Estimation at Low Speeds for Torque MRAS-Based Sensorless Induction Motor Drives", IEEE Transactions on Energy Conversion, Vol.31, No.1, pp.270 282, 2016. 